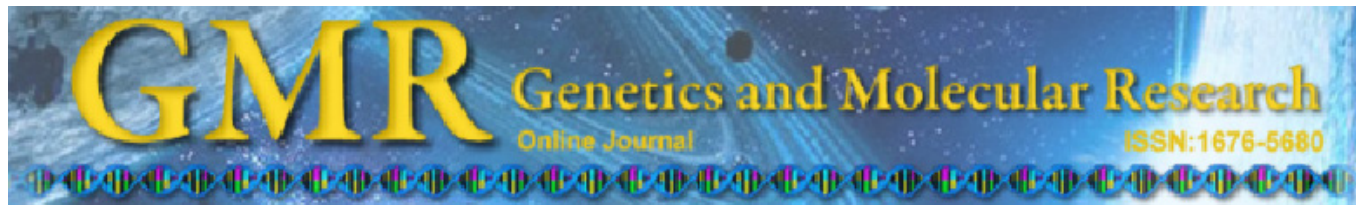

\title{
Association between XPD Lys751Gln polymorphism and risk of head and neck cancer: a meta-analysis
}

\author{
H. Yuan, Y.M. Niu, R.X. Wang, H.Z. Li and N. Chen \\ Institute of Dental Research, Nanjing Medical University, Nanjing, P.R. China \\ Corresponding author: N. Chen \\ E-mail:ningchen09@gmail.com
}

Genet. Mol. Res. 10 (4): 3356-3364 (2011)

Received March 29, 2011

Accepted August 15, 2011

Published November 22, 2011

DOI http://dx.doi.org/10.4238/2011.November.22.6

\begin{abstract}
Several studies have investigated the association between Lys751Gln polymorphism in the xeroderma pigmentosum group D $(X P D)$ gene and risk of head and neck cancer; however, the published results are conflicting. We conducted a meta-analysis that comprised 15 published case-control studies examining the association of head and neck cancer risk with XPD Lys751Gln polymorphism in different populations, based on the data identified in Medline up to November 2010. Odds ratios (ORs) with $95 \%$ confidence intervals (CI) were used to assess the strength of the association. Overall, significantly elevated head and neck cancer risk was associated with XPD Lys $751 \mathrm{Gln}$ polymorphism when all studies were pooled into the meta-analysis $[(\mathrm{Gln} / \mathrm{Gln}+\mathrm{Lys} /$ Gln) $v s$ Lys $/$ Lys: $\mathrm{OR}=1.12,95 \% \mathrm{CI}=1.03-1.22, \mathrm{P}<0.01$, heterogeneity $\mathrm{P}=0.11]$. In the subgroup analysis by ethnicity, borderline significantly increased risk was found for Europeans [(Gln/Gln + Lys/Gln) $v s$ Lys/ Lys: $\mathrm{OR}=1.11,95 \% \mathrm{CI}=1.00-1.23, \mathrm{P}<0.05]$. In conclusion, our metaanalysis demonstrated that XPD Lys751Gln polymorphism could be a prediction marker for risk of head and neck cancer.
\end{abstract}

Key words: Polymorphism; Head and neck cancer; Meta-analysis; XPD 


\section{INTRODUCTION}

Head and neck cancer (HNC) is one of most common cancers worldwide. It constitutes about $5 \%$ of all cancers in the US and the incidence is similar in most developed and developing countries. Smoking and alcohol consumption are well-recognized risk factors for $\mathrm{HNC}$. It has been reported that HNC is much more common in smokers Fthan in non-smokers and most common in males over 50 years of age (Kamangar et al., 2006; American Cancer Society, 2007). Specifically, cancers in the mouth and throat are about six times more common in smokers than in non-smokers, increasing to about 15 times if the smokers are also heavy drinkers (Blot et al., 1988; Lichtenstein et al., 2000; Schottenfeld and Fraumeni, 2006). Furthermore, candidate gene association studies also provide cumulative evidence that genetic factors including family history and polymorphisms in genes, such as DNA repair genes, play an important role in the development of HNC.

Many environmental factors, such as radiation, diet, smoking, and endogenous or exogenous estrogens, are associated with DNA damage (Schottenfeld and Fraumeni, 2006). Unrepaired or misrepaired DNA results in gene mutations, chromosomal alterations and genomic instability. Several studies have suggested that genes involved in the DNA repair system play a crucial role in protecting against mutations and patients with certain cancers have reduced DNA repair capacity (Goode et al., 2002). Associations between polymorphisms in several DNA repair genes and risks of multiple cancers have been extensively examined. Of those, xeroderma pigmentosum group $\mathrm{D}(X P D)$, also known as excision repair cross-complementing group 2 (ERCC2), is one of eight nucleotide excision repair (NER) core genes (i.e., ERCC1, $X P A, X P B / E R C C 3, X P C, X P D / E R C C 2, X P E / D D B 1, X P F / E R C C 4$ and XPG/ERCC5). The XPD protein is a DNA helicase and an essential part of the TFIIH transcription factor complex. Some studies have suggested that polymorphisms in XPD may be associated with reduced DNA repair due to a possible reduction in helicase activity (Schaeffer et al., 1994; Coin et al., 1998; Winkler et al., 2000). One of the common XPD polymorphisms is Lys $751 \mathrm{Gln}$ (rs13181) in exon 23. It has been reported that this amino acid change in exon 23 may lead to loss of an acidic residue and a complete change in the electronic configuration of the amino acid (de Boer and Hoeijmakers, 2000; Pastorelli et al., 2002).

A number of studies have investigated the effect of XPD Lys751Gln polymorphism on HNC risk; however, the results remain conflicting rather than conclusive (Sturgis et al., 2000; Rydzanicz et al., 2005; Huang et al., 2005; Kietthubthew et al., 2006; Matullo et al., 2006; Ramachandran et al., 2006; Bau et al., 2007; An et al., 2007; Majumder et al., 2007; Harth et al., 2008; Abbasi et al., 2009; Mitra et al., 2009; Jelonek et al., 2010; Ji et al., 2010; Sliwinski et al., 2011). Therefore, we performed a meta-analysis including 15 published casecontrol studies to assess the overall relationship between the XPD Lys $751 \mathrm{Gln}$ polymorphism and $\mathrm{HNC}$ risk.

\section{MATERIAL AND METHODS}

\section{Search strategy}

The PubMed database was searched with the terms "head and neck cancer", "oral cancer", "oropharyngeal cancer", "laryngeal cancer", "pharyngeal cancer", "XPD”, “excision 
repair cross-complementing group 2", and "polymorphism" (last search update February 2011). We also used the PubMed option "Related Articles" to identify additional studies on the same topic. Reference lists in retrieved articles were also screened. All selected studies should fulfill the following two criteria: a) case-control studies on XPD Lys751Gln polymorphism and $\mathrm{HNC}$ risk; b) sufficient published data for estimating an odds ratio (OR) with 95\% confidence interval (CI). We selected the largest or most recent publication (Little et al., 2002) if multiple publications reported on the same or overlapping data.

\section{Data extraction}

The following information was extracted from each included publication: the first author's name, publication data, sources of controls, racial descent of the study population (categorized as Asian or European), genotyping method and number of cases and controls with different genotypes, and P value for Hardy-Weinberg equilibrium (HWE).

\section{Statistical analysis}

Crude ORs with $95 \%$ CIs were computed to assess the strength of relationship between the XPD Lys751Gln polymorphism and HNC risk. The pooled ORs were performed for the allele contrast (Gln vs Lys), co-dominant model (Gln/Gln vs Lys/Lys, Lys/Gln vs Lys/ Lys), dominant model [(Gln/Gln + Lys) / Gln vs Lys/Lys], and recessive model [Gln/Gln vs (Lys/Lys + Lys/Gln)], respectively. In addition, we conducted the stratification analysis in Asians and Europeans. Heterogeneity assumption was assessed by the chi-square based Q-test (Lau et al., 1997). The pooled OR estimation of each study was calculated by the random-effects model (the DerSimonian and Laird method) when $\mathrm{P}<0.10$; otherwise, the fixed-effects model (the Mantel-Haenszel method) was used (DerSimonian and Laird, 1986). The potential publication bias was estimated by Egger's linear regression test by visual inspection of the Funnel plot (Egger et al., 1997). Statistical analysis was performed using the Statistical Analysis System software (v.9.1.3; SAS Institute, Cary, NC) and Review Manage (v.4.2; Oxford, England), using two-sided P values.

\section{RESULTS}

\section{Study characteristic}

A total of 15 eligible case-control studies on the association between XPD Lys $751 \mathrm{Gln}$ polymorphism and HNC risk were included for this meta-analysis (Sturgis et al., 2000; Rydzanicz et al., 2005; Huang et al., 2005; Kietthubthew et al., 2006; Matullo et al., 2006; Ramachandran et al., 2006; Bau et al., 2007; An et al., 2007; Majumder et al., 2007; Harth et al., 2008; Abbasi et al., 2009; Mitra et al., 2009; Jelonek et al., 2010; Ji et al., 2010; Sliwinski et al., 2011). Table 1 presents the main characteristics of these studies. There were 9 studies of European populations and 6 studies of Asians. Diverse genotyping methods included PCR-RFLP and TaqMan. All studies indicated that the distribution of genotypes in the controls was consistent with HWE except two (Abbasi et al., 2009; Jelonek et al., 2010). 


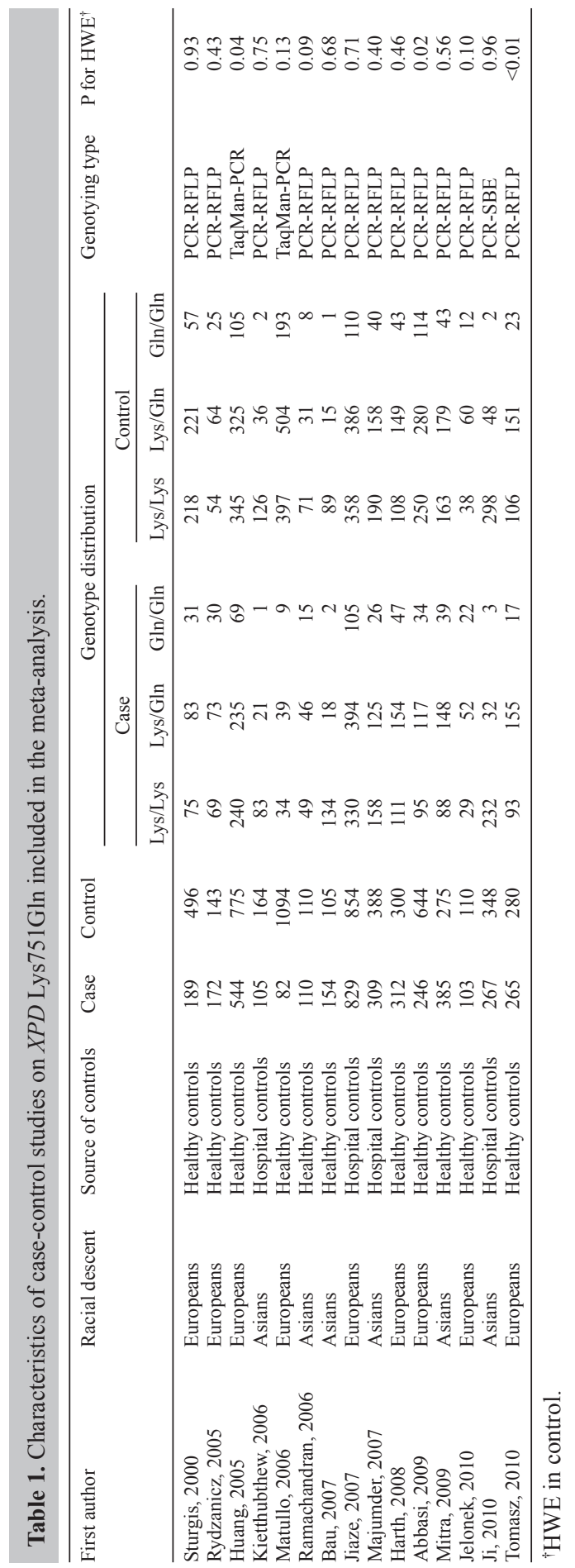




\section{Meta-analysis}

The main results of this meta-analysis and the heterogeneity test are shown in Table 2. Overall, we found a significant association of $X P D$ Lys $751 \mathrm{Gln}$ polymorphism with HNC risk for the dominant comparison $[(\mathrm{Gln} / \mathrm{Gln}+\mathrm{Lys} / \mathrm{Gln})$ vs Lys/Lys: $\mathrm{OR}=1.12,95 \% \mathrm{CI}=$ $1.03-1.22, \mathrm{P}=0.01$, heterogeneity $\mathrm{P}=0.11$, Figure 1] and borderline significantly increased risk was found in heterozygote comparison (Lys/Gln $v s$ Lys/Lys: $\mathrm{OR}=1.08,95 \% \mathrm{CI}=0.99$ $1.19, \mathrm{P}=0.08$, heterogeneity $\mathrm{P}=0.47$, Figure 2 ). However, such associations were not found in other comparisons [Gln $v$ s Lys: $\mathrm{OR}=1.04,95 \% \mathrm{CI}=0.93-1.15, \mathrm{P}=0.51$, heterogeneity $\mathrm{P}=0.006 ; \mathrm{Gln} / \mathrm{Gln} v s$ Lys/Lys: $\mathrm{OR}=1.06,95 \% \mathrm{CI}=0.92-1.22, \mathrm{P}=0.45$, heterogeneity $\mathrm{P}=$ $0.12 ; \mathrm{Gln} / \mathrm{Gln} v s(\mathrm{Lys} / \mathrm{Lys}+\mathrm{Lys} / \mathrm{Gln}): \mathrm{OR}=0.98,95 \% \mathrm{CI}=0.86-1.12, \mathrm{P}=0.75$, heterogeneity $\mathrm{P}=0.16]$. In the stratified analysis by ethnicity, we only found a borderline association of XPD Lys751Gln polymorphism with $\mathrm{HNC}$ risk in European populations [ $(\mathrm{Gln} / \mathrm{Gln}+\mathrm{Lys} /$ Gln) $v s$ Lys/Lys: $\mathrm{OR}=1.11,95 \% \mathrm{CI}=1.00-1.23, \mathrm{P}=0.05$, heterogeneity $\mathrm{P}=0.62$ ), but not in Asian populations. Sensitivity analysis was carried out by limiting the meta-analysis to those studies fulfilling HWE and the results in any genetic model were not materially altered (data not shown).

\begin{tabular}{|c|c|c|c|c|}
\hline Contrast & Racial descent & OR & $95 \% \mathrm{CI}$ & $\mathrm{P}^{*}$ \\
\hline \multirow[t]{3}{*}{ Gln $v s$ Lys } & Total & 1.04 & $0.93-1.15$ & $<0.01^{\dagger}$ \\
\hline & Asian & 1.02 & $0.75-1.40$ & $<0.01^{\dagger}$ \\
\hline & European & 1.02 & $0.95-1.10$ & 0.38 \\
\hline \multirow[t]{3}{*}{ Gln/Gln vs Lys/Lys } & Total & 1.06 & $0.92-1.22$ & 0.12 \\
\hline & Asian & 1.31 & $0.95-1.82$ & 0.21 \\
\hline & European & 1.00 & $0.86-1.17$ & 0.19 \\
\hline \multirow[t]{3}{*}{ Lys/Gln $v s$ Lys/Lys } & Total & 1.08 & $0.99-1.19$ & 0.47 \\
\hline & Asian & 1.13 & $0.84-1.52$ & $0.04^{\dagger}$ \\
\hline & European & 1.06 & $0.96-1.19$ & 0.99 \\
\hline \multirow[t]{3}{*}{ (Gln/Gln + Lys/Gln) vs Lys/Lys } & Total & 1.12 & $1.03-1.22$ & 0.11 \\
\hline & Asian & 1.15 & $0.84-1.57$ & $0.01^{\dagger}$ \\
\hline & European & 1.11 & $1.00-1.23$ & 0.62 \\
\hline \multirow[t]{3}{*}{$\mathrm{Gln} / \mathrm{Gln} v s(\mathrm{Lys} / \mathrm{Lys}+\mathrm{Lys} / \mathrm{Gln})$} & Total & 0.98 & $0.86-1.12$ & 0.16 \\
\hline & Asian & 1.16 & $0.85-1.58$ & 0.53 \\
\hline & European & 0.96 & $0.78-1.18$ & $0.09^{\dagger}$ \\
\hline
\end{tabular}

*Test for heterogeneity. ${ }^{\dagger}$ Estimates for random effects model.

\section{Publication bias}

Funnel plot and Egger's test were performed to estimate the publication bias of literatures. The shapes of the funnel plots in all genetic models did not reveal any evidence of obvious asymmetry. Figure 3 shows the shape of the funnel plots of the dominant model (Gln/ Gln + Lys/Gln vs Lys/Lys) in all populations and the result was further supported by Egger's tests $[\mathrm{P}=0.31$ for $(\mathrm{Gln} / \mathrm{Gln}+\mathrm{Lys} / \mathrm{Gln}) v s \mathrm{Lys} / \mathrm{Lys}]$. 


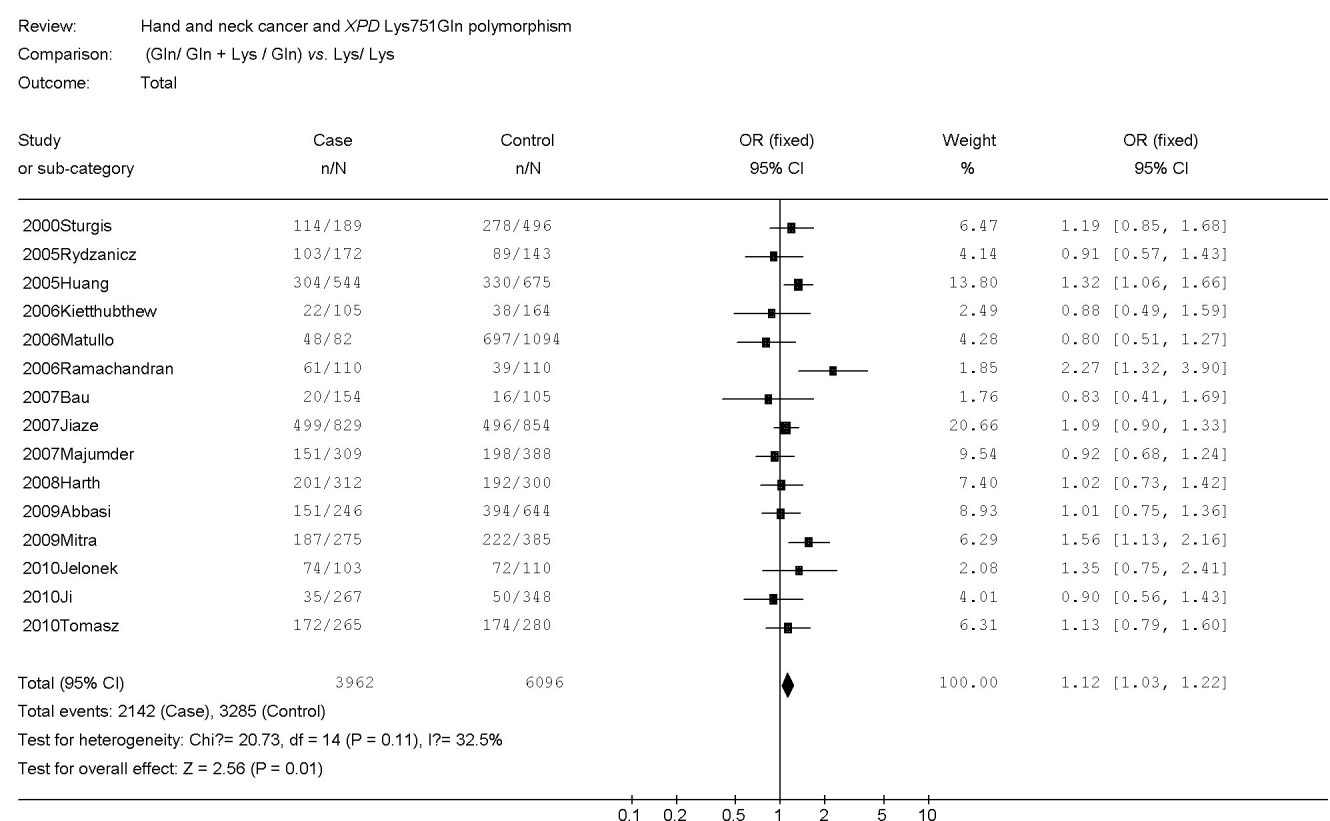

Figure 1. ORs of HNC cancer associated with XPD Lys $751 \mathrm{Gln}$ polymorphism for the Gln/Gln + Lys/Gln genotype compared with the Lys/Lys genotype.

\begin{tabular}{|c|c|c|c|c|c|c|}
\hline Review: & \multicolumn{6}{|c|}{ Hand and neck cancer and XPD Lys751GIn polymorphism } \\
\hline Comparison: Ly & \multicolumn{6}{|c|}{ Lys/ GIn vs. Lys/ Lys } \\
\hline Outcome: & \multicolumn{6}{|c|}{ Total } \\
\hline \multirow{2}{*}{$\begin{array}{l}\text { Study } \\
\text { or sub-category }\end{array}$} & \multirow{2}{*}{$\begin{array}{c}\text { Case } \\
n / N\end{array}$} & \multirow{2}{*}{$\begin{array}{c}\text { Control } \\
n / N\end{array}$} & \multirow{2}{*}{$\begin{array}{l}\text { OR (fixed) } \\
95 \% \mathrm{Cl}\end{array}$} & \multirow{2}{*}{$\begin{array}{c}\text { Weight } \\
\%\end{array}$} & \multicolumn{2}{|r|}{ OR (fixed) } \\
\hline & & & & & & $95 \% \mathrm{Cl}$ \\
\hline 2000Sturgis & $83 / 158$ & $221 / 439$ & & 6.39 & 1.09 & {$[0.76,1.57]$} \\
\hline 2005Rydzanicz & $73 / 142$ & $64 / 118$ & $\rightarrow$ & 3.91 & 0.89 & {$[0.55,1.46]$} \\
\hline 2005Huang & $235 / 475$ & $325 / 670$ & & 15.69 & 1.04 & {$[0.82,1.32]$} \\
\hline 2006Kietthubthew & $21 / 104$ & $36 / 162$ & $\longrightarrow$ & 2.59 & 0.89 & {$[0.48,1.62]$} \\
\hline 2006 Matullo & $39 / 73$ & $504 / 901$ & $\rightarrow-$ & 4.05 & 0.90 & {$[0.56,1.46]$} \\
\hline 2006Ramachandra & $46 / 95$ & $31 / 102$ & $\longrightarrow$ & 1.78 & 2.15 & {$[1.20,3.85]$} \\
\hline 2007Bau & $18 / 152$ & $15 / 104$ & $\longrightarrow$ & 1.81 & 0.80 & {$[0.38,1.66]$} \\
\hline 2007Jiaze & $394 / 724$ & $386 / 744$ & - & 19.99 & 1.11 & {$[0.90,1.36]$} \\
\hline 2007Majumder & $125 / 283$ & $158 / 34$ 日 & $\rightarrow-$ & 9.11 & 0.95 & {$[0.69,1.30]$} \\
\hline 2008 Harth & $154 / 265$ & $149 / 257$ & $\rightarrow-$ & 7.30 & 1.01 & {$[0.71,1.42]$} \\
\hline 2009Abbasi & $117 / 212$ & $280 / 530$ & - & 8.26 & 1.10 & {$[0.80,1.51]$} \\
\hline 2009Mitra & $148 / 236$ & $179 / 342$ & $\rightarrow-$ & 6.28 & 1.53 & {$[1.09,2.15]$} \\
\hline 2010Jelonek & $52 / 81$ & $60 / 98$ & $\longrightarrow$ & 2.24 & 1.14 & {$[0.62,2.09]$} \\
\hline $2010 \mathrm{Ji}$ & $32 / 264$ & $48 / 346$ & $\rightarrow-$ & 4.20 & 0.86 & {$[0.53,1.38]$} \\
\hline 2010Tomasz & $155 / 248$ & $151 / 257$ & - & 6.40 & 1.17 & {$[0.82,1.67]$} \\
\hline Total $(95 \% \mathrm{Cl})$ & 3512 & 5418 & $\varphi$ & 100.00 & 1.08 & {$[0.99,1.19]$} \\
\hline \multicolumn{7}{|c|}{ Total events: 1692 (Case), 2607 (Control) } \\
\hline \multicolumn{7}{|c|}{ Test for heterogeneity: Chi?= $13.70, \mathrm{df}=14(P=0.47), 1 ?=0 \%$} \\
\hline \multicolumn{7}{|c|}{ Test for overall effect: $Z=1.73(P=0.08)$} \\
\hline
\end{tabular}

Figure 2. OR of HNC cancer associated with XPD Lys751Gln polymorphism for the Lys/Gln genotype compared with the Lys/Lys genotype in total. 


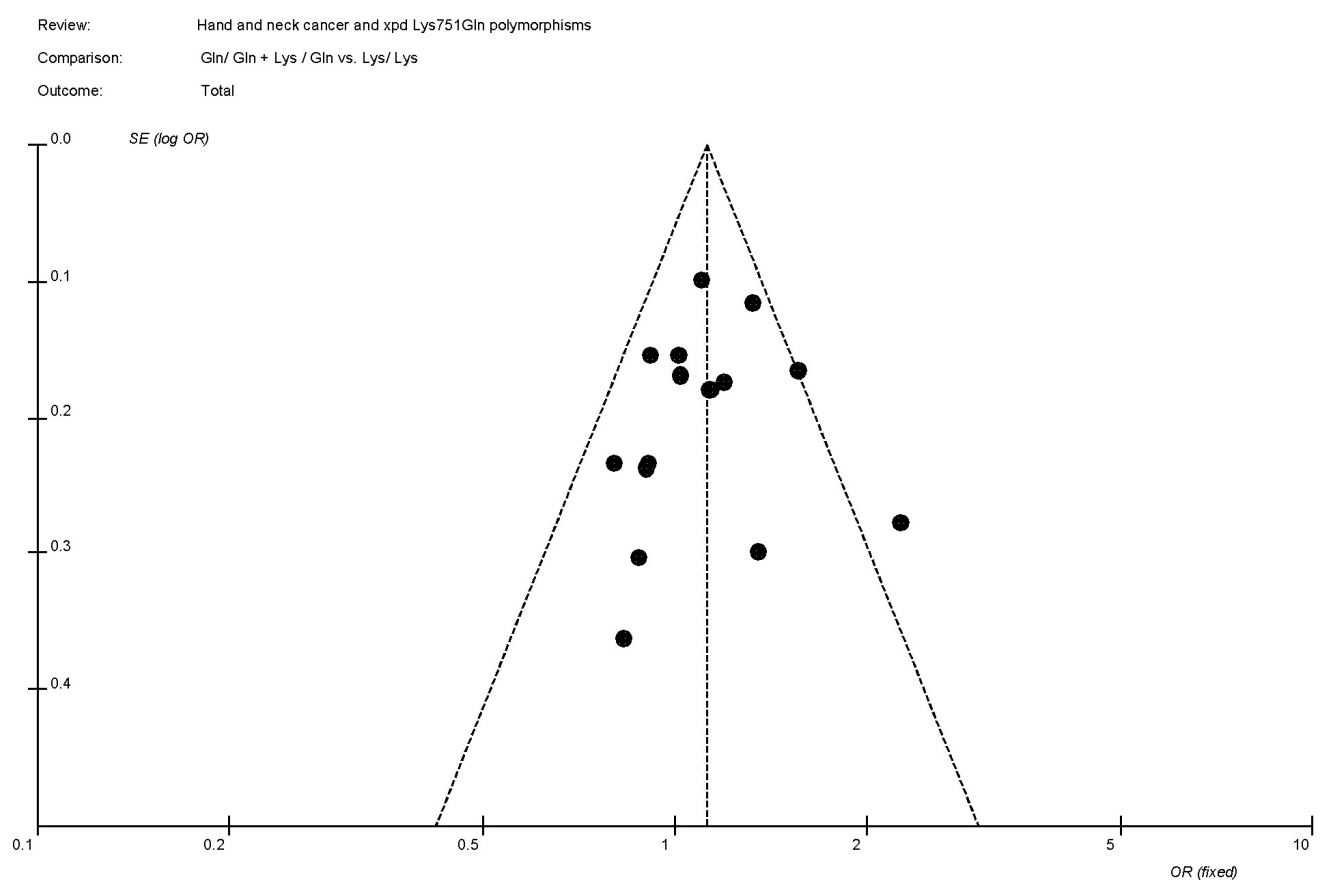

Figure 3. Funnel plot analysis to detect publication bias. Each point represents a separate study for the indicated association.

\section{DISCUSSION}

$X P D$ gene maps to chromosome $19 \mathrm{q} 13.3$ and is composed of 23 exons. Its protein consists of 761 amino acids in length (Flejter et al., 1992) and is involved in transcription-coupled NER by acting as an integral member of the basal transcription factor BTF2/TFIIH complex (Schaeffer et al., 1994; Winkler et al., 2000). The XPD product has an ATP-dependent DNA helicase activity and belongs to the RAD3/XPD subfamily of helicases. Mutations in the XPD gene can result in three different disorders: xeroderma pigmentosum, trichothiodystrophy, and Cockayne syndrome (de Boer and Hoeijmakers, 2000). Correlation of its polymorphisms and cancer risk has been studied, but the results remain controversial.

Sturgis et al. (2000) reported that $13181 \mathrm{CC}$ was associated with a borderline increased risk (adjusted $\mathrm{OR}=1.55 ; 95 \% \mathrm{CI}=0.96-2.52$ ) of $\mathrm{SCCHN}$ and it was higher in older subjects $(\mathrm{OR}=2.22 ; 95 \% \mathrm{CI}=1.03-4.80)$ and current drinkers $(\mathrm{OR}=2.59 ; 95 \% \mathrm{CI}=1.25-5.34)$. Mitra et al. (2009) found statistically significant increased SCCHN risk in individuals with the variant genotypes of rs13181: $(\mathrm{OR}=1.680,95 \% \mathrm{CI} 1.014$ to 2.784$),(\mathrm{OR}=1.531,95 \% \mathrm{CI} 1.092$ to 2.149$)$ and $(\mathrm{OR}=1.560,95 \% \mathrm{CI} 1.128$ to 2.158$)$. The others came to a different conclusion. Huang et al. (2005) found that XPD751 was not associated with $\mathrm{HNC}$ risk $(\mathrm{OR}=1.10 ; 95 \% \mathrm{CI}$, 0.83-1.45). We pooled the results of the 15 eligible case-control studies in this meta-analysis and found a significant association of XPD Lys $751 \mathrm{Gln}$ polymorphism with $\mathrm{HNC}$ risk in total populations. In the subgroup analysis based on ethnicities, borderline associations were found 
under the dominant model, suggesting that $X P D$ Lys $751 \mathrm{Gln}$ polymorphism play similar roles in Europeans.

There are some limitations that should be addressed. First, these results were based on unadjusted estimates, and the lack of original data from the eligible studies limited the evaluation of the effects of the gene-gene and gene-environment interactions in HNC development. Second, the sample size is still relatively small. Thus, we did not have enough statistical power to find the real relationship between XPD polymorphism and HNC risk. Finally, it is well known that each gene has only a moderate effect on HNC development. The combinations of certain genotypes may be more discriminating as risk factors than a single locus.

In conclusion, despite these limitations, we found XPD Lys751Gln polymorphism may contribute to HNC susceptibility in the pooled population. Large-scale case-control and population-based association studies are warranted to validate the risk identified in the current meta-analysis and investigate the potential gene-gene and gene-environment interactions on $\mathrm{HNC}$ risk.

\section{ACKNOWLEDGMENTS}

We are grateful to Dr. Hongxia Ma for his assistance with statistics. Research supported by grants from the Medical Development Foundation of Health Department of Jiangsu Province (\#H200811) and the Natural Science Foundation of Jiangsu Higher Education Institutions (\#08KJB320008).

\section{Conflict of interest}

None declared.

\section{REFERENCES}

Abbasi R, Ramroth H, Becher H, Dietz A, et al. (2009). Laryngeal cancer risk associated with smoking and alcohol consumption is modified by genetic polymorphisms in ERCC5, ERCC6 and RAD23B but not by polymorphisms in five other nucleotide excision repair genes. Int. J. Cancer 125: 1431-1439.

American Cancer Society (2007). Cancer Facts \& Figures 2007. CA: American Cancer Society, Oakland.

An J, Liu Z, Hu Z, Li G, et al. (2007). Potentially functional single nucleotide polymorphisms in the core nucleotide excision repair genes and risk of squamous cell carcinoma of the head and neck. Canc. Epidemiol. Biomarkers Prev. 16: $1633-1638$

Bau DT, Tsai MH, Huang CY, Lee CC, et al. (2007). Relationship between polymorphisms of nucleotide excision repair genes and oral cancer risk in Taiwan: evidence for modification of smoking habit. Chin. J. Physiol. 50: 294-300.

Blot WJ, McLaughlin JK, Winn DM, Austin DF, et al. (1988). Smoking and drinking in relation to oral and pharyngeal cancer. Cancer Res. 48: 3282-3287.

Coin F, Marinoni JC, Rodolfo C, Fribourg S, et al. (1998). Mutations in the XPD helicase gene result in XP and TTD phenotypes, preventing interaction between XPD and the p44 subunit of TFIIH. Nat. Genet. 20: 184-188.

de Boer J and Hoeijmakers JH (2000). Nucleotide excision repair and human syndromes. Carcinogenesis 21: 453-460.

DerSimonian R and Laird N (1986). Meta-analysis in clinical trials. Control Clin. Trials 7: 177-188.

Egger M, Davey SG, Schneider M and Minder C (1997). Bias in meta-analysis detected by a simple, graphical test. BMJ 315: 629-634.

Flejter WL, McDaniel LD, Johns D, Friedberg EC, et al. (1992). Correction of xeroderma pigmentosum complementation group D mutant cell phenotypes by chromosome and gene transfer: involvement of the human ERCC2 DNA repair gene. Proc. Natl. Acad. Sci. U. S. A. 89: 261-265.

Goode EL, Ulrich CM and Potter JD (2002). Polymorphisms in DNA repair genes and associations with cancer risk. Canc. 
Epidemiol. Biomarkers Prev. 11: 1513-1530.

Harth V, Schafer M, Abel J, Maintz L, et al. (2008). Head and neck squamous-cell cancer and its association with polymorphic enzymes of xenobiotic metabolism and repair. J. Toxicol. Environ. Health A. 71: 887-897.

Huang WY, Olshan AF, Schwartz SM, Berndt SI, et al. (2005). Selected genetic polymorphisms in MGMT, XRCC1, XPD, and XRCC3 and risk of head and neck cancer: a pooled analysis. Canc. Epidemiol. Biomarkers Prev. 14: $1747-1753$.

Jelonek K, Gdowicz-Klosok A, Pietrowska M, Borkowska M, et al. (2010). Association between single-nucleotide polymorphisms of selected genes involved in the response to DNA damage and risk of colon, head and neck, and breast cancers in a Polish population. J. Appl. Genet. 51: 343-352.

Ji YB, Tae K, Lee YS, Lee SH, et al. (2010). XPD polymorphisms and risk of Squamous cell Carcinoma of the head and neck in a Korean sample. Clin. Exp. Otorhinolaryngol. 3: 42-47.

Kamangar F, Dores GM and Anderson WF (2006). Patterns of cancer incidence, mortality, and prevalence across five continents: defining priorities to reduce cancer disparities in different geographic regions of the world. J. Clin. Oncol. 24: $2137-2150$.

Kietthubthew S, Sriplung H, Au WW and Ishida T (2006). Polymorphism in DNA repair genes and oral squamous cell carcinoma in Thailand. Int. J. Hyg. Environ. Health 209: 21-29.

Lau J, Ioannidis JP and Schmid CH (1997). Quantitative synthesis in systematic reviews. Ann. Intern. Med. 127: 820-826.

Lichtenstein P, Holm NV, Verkasalo PK, Iliadou A, et al. (2000). Environmental and heritable factors in the causation of cancer - analyses of cohorts of twins from Sweden, Denmark, and Finland. N. Engl. J. Med. 343: 78-85.

Little J, Bradley L, Bray MS, Clyne M, et al. (2002). Reporting, appraising, and integrating data on genotype prevalence and gene-disease associations. Am. J. Epidemiol. 156: 300-310.

Majumder M, Sikdar N, Ghosh S and Roy B (2007). Polymorphisms at XPD and XRCC1 DNA repair loci and increased risk of oral leukoplakia and cancer among NAT2 slow acetylators. Int. J. Cancer 120: 2148-2156.

Matullo G, Dunning AM, Guarrera S, Baynes C, et al. (2006). DNA repair polymorphisms and cancer risk in non-smokers in a cohort study. Carcinogenesis 27: 997-1007.

Mitra AK, Singh N, Garg VK, Chaturvedi R, et al. (2009). Statistically significant association of the single nucleotide polymorphism (SNP) rs13181 (ERCC2) with predisposition to Squamous Cell Carcinomas of the Head and Neck (SCCHN) and Breast cancer in the north Indian population. J. Exp. Clin. Cancer Res. 28: 104.

Pastorelli R, Cerri A, Mezzetti M, Consonni E, et al. (2002). Effect of DNA repair gene polymorphisms on BPDE-DNA adducts in human lymphocytes. Int. J. Cancer 100: 9-13.

Ramachandran S, Ramadas K, Hariharan R, Rejnish KR, et al. (2006). Single nucleotide polymorphisms of DNA repair genes XRCC1 and XPD and its molecular mapping in Indian oral cancer. Oral Oncol. 42: 350-362.

Rydzanicz M, Wierzbicka M, Gajecka M, Szyfter W, et al. (2005). The impact of genetic factors on the incidence of multiple primary tumors (MPT) of the head and neck. Cancer Lett. 224: 263-278.

Schaeffer L, Moncollin V, Roy R, Staub A, et al. (1994). The ERCC2/DNA repair protein is associated with the class II BTF2/TFIIH transcription factor. EMBO J. 13: 2388-2392.

Schottenfeld D and Fraumeni JF (2006). Cancer Epidemiology and Prevention, 3rd edn. Oxford University Press, New York.

Sliwinski T, Przybylowska K, Markiewicz L, Rusin P, et al. (2011). MUTYH Tyr165Cys, OGG1 Ser326Cys and XPD Lys751Gln polymorphisms and head neck cancer susceptibility: a case control study. Mol. Biol. Rep. 38: 1251-1261.

Sturgis EM, Zheng R, Li L, Castillo EJ, et al. (2000). XPD/ERCC2 polymorphisms and risk of head and neck cancer: a case-control analysis. Carcinogenesis 21: 2219-2223.

Winkler GS, Araujo SJ, Fiedler U, Vermeulen W, et al. (2000). TFIIH with inactive XPD helicase functions in transcription initiation but is defective in DNA repair. J. Biol. Chem. 275: 4258-4266. 